\title{
COMPARATIVE STUDY OF INTRALESIONAL TRIAMCINOLONE ALONE AND COMBINATION OF TRIAMCINOLONE PLUS 5-FLUROURACIL FOR THE TREATMENT OF KELOID AND HYPERTROPHIC SCAR
}

\author{
BEGUM ST $^{1}$, ZAKARIA ASM ${ }^{2}$
}

\begin{abstract}
Context: Keloids and hypertrophic scars are a common problem with significant recurrence rates despite intralesional steroid treatment and multimodal therapy.The purpose of this study was to evaluate the efficacy of using a 5-fluorouracil (5-FU) alone and along with steroid mixture to treat keloids and hypertrophic scars comparing the results with use of steroid treatment alone.
\end{abstract}

Methods: Patient charts from July 2009 to January 2010 were reviewed. Patients were stratified into 2 groups: group A (triamcinolone) and group B (5-FU+ triamcinolone). The percentage of lesion size reduction and symptoms were evaluated.

Results: A total of 60 patients with keloids and hypertrophic scars were divided in two groups. Patients who underwent 5-FU+triamcinolone combination had similar response from the group of patients who did not receive 5-FU. Differences in complication rates were not statistically significant.

Conclusion: Combination 5-FU+triamcinolone were comparable to intralesional steroid therapy in the treatment of keloids. Side effects were negligible.

Keywords: Keloid, hypertrophic scar, steroid, triamcinolone, 5-flurouracil.

J Dhaka Med Coll. 2012; 21(1) : 46-54.

\section{Introduction:}

Keloids and hypertrophic scars are benign hyper proliferative growths of dermal fibroblasts ${ }^{1}$. Patients with these skin problems often experience marked physical deformity, restricted range of motion, pain, pruritus and psychological problems due to cosmetic concern $^{2}$. Although the basis for keloid and hypertrophic scar formation has not been fully elucidated, it has been suggested that fibroblasts of keloid and hypertrophic scar tissue produce increased amounts of collagen compared with normal fibroblasts ${ }^{3}$. Thus, suppression of the overwhelming and uncontrolled fibroblast activity in keloid and hypertrophic scar may be essential in therapeutic approaches to these abnormal wound responses ${ }^{4}$. Increased vascularity has also been found in keloid tissue ${ }^{2,5}$. Keloid as well as hypertrophic scar is the result of excessive wound healing. Traditionally, hypertrophic scars are defined as scars that have not over grown the original wound boundaries but are instead raised. They are usually self-limited type of over healing that can regress with time on the other hand; keloids are scars that overgrow the original wound edges. The cytokine transforming growth factor (TGF)-b has been implicated in the pathogenesis of keloid ${ }^{6,7}$.It is likely that the combination of raised levels of TGF- $b$ and the abnormal response of proliferative scar fibroblasts to this cytokine are important for keloid formation ${ }^{8}$. There is no universally accepted treatment resulting in permanent hypertrophic or keloid scar ablation. Although

1. Dr. Syeda Tania Begum, Senior Registrar, Department of Skin \& VD, Bangladesh Institute of Health Science (BIHS), Dhaka.

2. Dr. ASM Zakaria, Associate Professor, Department of Dermatology and Venereology, Bangabandhu Sheikh Mujib Medical University (BSMMU), Dhaka.

Correspondence : Dr. Syeda Tania Begum, Senior Registrar, Department of Skin \& VD, Bangladesh Institute of health Science (BIHS), Mirpur, Dhaka. 
there is a lack of consensus about an ideal standard therapy, there is a significant need for an effective treatment protocol because keloids are common and tend to recur ${ }^{9}$. Despite the vast array of keloid therapies, there are still a significant number of treatment failures and a substantial inconsistency in the reproducibility of results. The ideal treatment would have a low side effect profile and be cost effective and easy to administer without the need of elaborate hardware. Traditionally, intralesional triamcinolone has been the mainstay of keloid treatment, in conjunction with re-excision and adjuvant therapies such as radiation and compression. Conventional therapy for keloids may yield a frustrating number of recurrences. In addition, the side effects of steroid injections are common and significant. Incidence of telangiectasias, hypopigmentation, and skin atrophy has been reported as high as $37 \%$ in one study ${ }^{10}$.Alternative therapies, such as laser or radiation therapy require significant hardware. The interest in antineoplastic agents as a therapeutic modality is logical, because keloids have been shown to exist in a hyper metabolic state. 5-Fluorouracil (5-FU), a pyrimidine analogue with antimetabolite activity, has been shown to inhibit fibroblast proliferation in tissue culture ${ }^{11-12}$. Both in vitro and in vivo studies have confirmed that 5fluorouracil (5-FU) inhibits collagen synthesis. It also has an inhibitory effect on TGF-binduced expression of the type I collagen gene in human fibroblasts 9 . In an effort to find out an alternative to intralesional triamcinolone, which causes significant skin atrophy study was directed to find out the efficacy of intralesional injection of 5-fluorouracil (5-FU) combined with triamcinolone compared to injection triamcinolone alone in treating keloids and hypertrophic scars. All the literature relating to the role of corticosteroids in keloid therapy suggests that a dose of 10-40 $\mathrm{mg} / \mathrm{ml}$ triamcinolone (TAC) is required to be effective in keloid. ${ }^{13}$ The mixture of corticosteroids triamcinolone (TAC) + 5fluorouracil (5-FU) combination would result in a concentration equivalent to $4 \mathrm{mg} / \mathrm{ml}$ triamcinolone which would not be expected to have any efficacy in treatment of patients. It was employed for its effect on potential 5fluorouracil (5- FU) induced inflammation. ${ }^{14}$ The present study was designed to see the efficacy of intralesional injection of 5fluorouracil (5-FU) combined with triamcinolone compared to injection triamcinolone alone in treating keloids and hypertrophic scars. To compare the percentage of height, length and width reduction after treatment compared with baseline height, length and width also reduction of percentage of erythema, induration and pruritus compared with baseline. To compare the adverse effects following treatment such as thinning /skin atrophy, telangiectasias, pigmentation, local ulceration.

\section{Methods:}

Study design: This study was a prospective, comparative and randomized clinical trial.

Place of study: This study was carried out in the Department of Dermatology and Venereology, Bangabandhu Sheikh Mujib Medical University (BSMMU), Dhaka.

Period of study: From July 2009 to January 2010.

Study population: Study included approximately 60 patients who attended with keloid and hypertrophic scars at outpatient department of Department of Dermatology and Venereology, Bangabandhu Sheikh Mujib Medical University (BSMMU), Dhaka.

\section{Inclusion criteria:}

i. Age: minimum 10 years,

ii. Lesions had to be a minimum of $10 \mathrm{~mm}$ in length,

iii. Only one lesion was treated per patient.

\section{Exclusion criteria:}

i. Patients who had received treatment within the past 6 months,

ii. Those with chronic renal failure,

iii. Those with any abnormalities in their liver function tests,

iv. Patients with abnormal complete blood count, 
v. Women who are pregnant, lactating or planning pregnancy in the near future,

vi. Infected and inflamed lesions,

vii. Non-cooperative patients.

Sample size: A total of 60 patients with keloid and hypertrophic scars was studied.

Sampling procedure: Simple random sampling.

Injection technique: The study was carried out by dividing the patients into group A and group B. Patients belonged to group A received injection triamcinolone (TAC) alone and patients belonged to group $B$ received intralesional 5-fluorouracil (5FU) combined with triamcinolone (TAC). Lesions had to be a minimum of $10 \mathrm{~mm}$ in length. Only one lesion (preferably on the trunk or proximal limb) was treated per patient. Patients were randomized into two study groups. A computer-generated table of random numbers was used for allocation In group A triamcinolone (TAC), all patients was treated once three weekly with intralesional triamcinolone (TAC) $10 \mathrm{mg}\{0.25$ $\mathrm{mL}$ of $40 \mathrm{mg} / \mathrm{mL}$ triamcinolone (TAC) diluted with $0.75 \mathrm{~mL}$ injectable normal saline\} for a total of four sessions. In group B \{Triamcinolone $(\mathrm{TAC})+5$-fluorouracil $(5-\mathrm{FU})\}$ patients was treated once three weekly with intralesional injection of triamcinolone (TAC) $4 \mathrm{mg}\{0.1 \mathrm{~mL}$ of $40 \mathrm{mg} / \mathrm{mL}$ triamcinolone (TAC) $\}$ mixed with 5-fluorouracil (5-FU) $45 \mathrm{mg}\{0.9 \mathrm{~mL}$ of $50 \mathrm{mg} / \mathrm{mL} 5$-fluorouracil(5-FU)\} for a total of four treatments. The solution was injected into the body of the keloid using a 25G needle until slight blanching clinically visible. The maximum volume of injection per $\mathrm{cm}^{2}$ will not exceed $0.5 \mathrm{ml}$. The delivered dose was adjusted according to the extent of the lesions, but not exceeding $2 \mathrm{ml}$ per session. Only the firm portion of the keloid was treated by multiple injections, separated by approximately $10 \mathrm{~mm}$. Injecting solutions was prepared and injected by investigator. Assessments of the lesions were performed at baseline and weeks 3, 6 and 12.

\section{Evaluation procedures:}

a. Length, width and height: Scars was marked on every patient and mapped using translucent paper at the first appointment to ensure the consistency of location. A dial calipers was used to determine greatest length, width and height of the lesion (millimeter). Percentage of flattening was defined as the percentage of height reduction after treatment compared with baseline height. Similar percentages was also be defined for reduction in length and width.

b. Erythema, induration and pruritus: Erythema and indurations will be graded by the observer and by the patients on a 5point scale $(0=$ no erythema, induration, or pruritus; 1 =mild; $2=$ moderate; $3=$ severe; 4=very severe erythema, induration, or pruritus). Percentages of lightening, softening and itch reduction were defined as the percentage of erythema, induration and pruritus reduction compared with baseline.

c. Skin atrophy, telangiectasias, pigmentation, ulceration: Skin atrophy was graded by the observer on a 5 point scale $(0=$ no atrophy; $1=$ mild atrophy; $2=$ moderate atrophy; $3=$ severe atrophy; $4=$ very severe atrophy). Telangiectasias, pigmentation, ulceration were observed clinically and noted if present.

All the data were recorded and analyzed by using SPSS version 13.0 between two treatment modalities.

\section{Results:}

In group A, 11(36.7\%) patients were below 25 years and $11(36.7 \%)$ patients between 26-35 years and $8(26.7 \%)$ patients were above 36 years. In group B, $11(36.7 \%)$ patients were below 25 years and $13(43.3 \%)$ patients between 2635 years and $6(20 \%)$ patients were above 36 years. Both groups age distribution is pretty similar (Table-I). In group A, 17 (56.7\%) patients were male and $13(43.30 \%)$ were female. In group B, 18 (60\%) patients were male and 12 $(40 \%)$ were female. The leading of the predisposing factors in both groups was trauma (56.7\% in group A and $40 \%$ in group B). The next leading cause in group A was infection $(20 \%)$ and in group B burn (Fig. 1). Other causes are acne, vaccination etc. Most of the patients 
in group A (56.7\%) and in group B (63.30\%) were history of lesion between 1-2 years. $16.7 \%$ in group A had history of less than 1 year and 26.7 $\%$ had history of lesions more than 2 years. In group B 20\% had duration of less than 1 year and $16.7 \%$ had history more that 2 years. Among the group A $66.67 \%$ and in group B $56.67 \%$ patients received no treatment previously. Steroid injections received in $16.67 \%$ in group A and $20 \%$ in group B patients. $10 \%$ in group A and $13.33 \%$ in group $B$ patients had undergone surgery. Others received topical steroid. Presenting local symptoms were almost similar in both groups. Percentage of symptoms was close to each other in both groups. $96.7 \%$ of the patients complained itching in both groups. Pain complained in $86.7 \%$ of patients in group A and $73.3 \%$ in group B. Cosmetic concern were $93.3 \%$ in group A and $83.3 \%$ in group B. Some of the patients in both groups complained about mechanical problems (Fig. 2). In group A, 60\% patients had previous family history and in group B $46.7 \%$ had positive family history. $\mathrm{P}$ value is $<0.301$ which is statistically insignificant in between two groups. Local examinations of the lesions done at the baseline or first day of the visit of the patients of the both groups are plotted in table. Mean lesion length was $44.67 \mathrm{~mm}$ in group $\mathrm{A}$ and $38.40 \mathrm{~mm}$ in group B. P value was 0.189 which was statistically insignificant. Mean lesion width was $26.10 \mathrm{~mm}$ in group A and $26.33 \mathrm{~mm}$ in group B. P value was 0.950 which was statistically insignificant. Mean lesion height was $4.22 \mathrm{~mm}$ in group $\mathrm{A}$ and $3.93 \mathrm{~mm}$ in group B. $P$ value was 0.314 which was statistically insignificant. These picture shows that both the groups of patients were evenly distributed and there was no significant statistical difference in between two groups (Table-II). Follow up of the patients done at 3 weeks, 6 weeks, 9 weeks and 12 weeks. Injections were given on baseline 3, 6 and 9 weeks. All the P values were above 0.05 . Thus there was no statistical difference in between two groups at any times. Lesions length, width and height were compared with baseline to 12 weeks follow up value (Fig. 3\&4). In group A, from baseline $44.67 \mathrm{~mm}$ lesion length decreased to $42.03 \mathrm{~mm}$ at 12 weeks. Therefore, $5.69 \%$ improvement was evident in length in group A. In group B, similar result was observed. From mean 38.40 $\mathrm{mm}$ of baseline lesions decreases to $36.33 \mathrm{~mm}$. There was $5.70 \%$ improvement in group B noted. Results in both groups were similar. $\mathrm{P}$ value was statistically insignificant. In group

Table-I

Age distribution in group $A(T A C)$ and $B(5-F U+T A C)$

\begin{tabular}{lccc}
\hline Age & $\begin{array}{c}\text { Triamcinolone (group A) } \\
\mathrm{n}(\%)\end{array}$ & $\begin{array}{c}\text { 5-Flurouracil+TAC (group B) } \\
\mathrm{n}(\%)\end{array}$ & Total \\
\hline Up to 25 years & $11(36.7)$ & $11(36.7)$ & 22 \\
$26-35$ years & $11(36.7)$ & $13(43.3)$ & 24 \\
$36+$ years & $8(26.7)$ & $6(20)$ & 14 \\
\hline Total & $30(100)$ & $30(100)$ & 60 \\
\hline
\end{tabular}

Table-II

Local examination of the lesions in group $A(T A C)$ and $B(5-F U+T A C)$

\begin{tabular}{|c|c|c|c|}
\hline Variable & $\begin{array}{c}\text { Triamicnolone } \\
(\text { Mean } \pm \text { SD) }\end{array}$ & $\begin{array}{c}\text { 5-Flurouracil+TAC } \\
(\text { Mean } \pm \mathrm{SD})\end{array}$ & P- value \\
\hline Length(mm) & $44.67 \pm 17.000$ & $38.40 \pm 19.431$ & 0.189 \\
\hline Width(mm) & $26.10 \pm 11.251$ & $26.33 \pm 16.705$ & 0.950 \\
\hline Height(mm) & $4.22 \pm .827$ & $3.93 \pm 1.285$ & 0.314 \\
\hline
\end{tabular}

*All the $\mathrm{p}$ values are above 0.05 thus there is no statistical difference in between two groups. 
A, from baseline $26.10 \mathrm{~mm}$ lesion width decreased to $23.63 \mathrm{~mm}$ at 12 weeks. Therefore, $9.46 \%$ improvement in group A observed. In group B, similar result was observed. From mean $26.33 \mathrm{~mm}$ of baseline lesions decreases to $22.43 \mathrm{~mm}$ at the end. In group B, $17.38 \%$ improvement was noted. Results in both groups were close to each other. $P$ value was statistically insignificant. In group $A$, from baseline $4.22 \mathrm{~mm}$ lesion height decreased to 12 weeks height was 0.70 . Height reduction $83.41 \%$ occurs in group A. In Group B, from baseline $3.93 \mathrm{~mm}$ lesion height decrease to 12 weeks height was 0.70 . In group $B$, there was $83.36 \%$ height reduction. Height reduction in both the groups was similar. $\mathrm{P}$ value was statistically insignificant (Table-III \& IV). Erythema score at baseline were graded in 5 point scale by investigator. In group A, 30\% patients graded as very severe group. $50 \%$ got severe erythema and $20 \%$ got moderate erythema. In 12 weeks follow up $76.7 \%$ showed no erythema and $23.3 \%$ showed mild erythema. $P$ value was $<0.0001$ which was highly significant. In group B, $16.7 \%$ patients had very severe erythema, $60 \%$ severe erythema, 20\% moderate erythema and $3.3 \%$ mild erythema at base line. On 12 weeks $83.3 \%$ in no erythema ans $16.7 \%$ in mild erythema. $P$ value was $<0.0001$ and highly significant. Induration score at baseline were graded in 5 point scale by investigator. In group A 30\% patients graded as very severe group. $53.3 \%$ got severe induration and $16.7 \%$ got moderate induration.
In 12 weeks, $36.7 \%$ patients got mild induration and $63.3 \% \%$ got no induration. $\mathrm{P}$ value was $<0.0001$ which was highly significant. In group B $16.7 \%$ patients got very severe induration, $53.3 \%$ got severe induration and $30 \%$ got moderate induration. After injection at 12 weeka follow up no induration noted in $66.7 \%$ cases. $33.3 \%$ showed mild induration. $\mathrm{P}$ value was $<0.0001$ which was highly significant. Pruritis score at baseline were graded in 5 point scale by investigator. In group A, 33.3\% patients graded as very severe group. $50 \%$ got severe pruritis and $16.7 \%$ got moderate pruritis. On 12 weeks $83.3 \%$ got no preritis and $16.7 \%$ got mild pruritis. $\mathrm{P}$ value was $<0.0001$ which was highly significant. In group B, $46.7 \%$ patients got very severe pruritis, $40 \%$ got severe pruritis and $10 \%$ got moderate pruritis. On 12 weeks $83.3 \%$ patients got no pruritis and $16.7 \%$ patients had mild pruritis. $P$ value is less then 0.0001 which was highly significant. In Group A, 20\% of patients showed telangiectasis. No patients in group B showed side effects of telangiectasis. In group A, hypopigmentation noted in $26.7 \%$ of the patients. In group $B$, no patients showed pigmentary change. No patients in group A showed ulceration. In group B, $56.7 \%$ of patients had ulceration. This is the most disturbing side effect in that group. Patients in group A complained skin atrophy 20 in 12 weeks. No patients in group B showed skin atrophy on 3 , 6, 9 and 12 weeks (Table-V).

Table-III

Follow up of the lesions in group A(TAC) and B(5-FU+TAC) (Length/Height/Width)

\begin{tabular}{lccc}
\hline & $\begin{array}{c}\text { Triamicnolone } \\
\text { Length }(\mathrm{mm})\end{array}$ & $\begin{array}{c}\text { 5-FU+ TAC } \\
\text { Mean } \pm \text { SD }\end{array}$ & $\begin{array}{c}\text { P value } \\
\text { Mean } \pm \text { SD }\end{array}$ \\
\hline 3 weeks & $44.40 \pm 17.02$ & $38.70 \pm 19.93$ & 0.238 \\
6 Weeks & $43.60 \pm 17.11$ & $37.33 \pm 19.74$ & 0.194 \\
9 Weeks & $42.67 \pm 17.08$ & $36.73 \pm 19.89$ & 0.220 \\
12 weeks & $42.03 \pm 17.15$ & $36.33 \pm 19.72$ & 0.237 \\
Width $(\mathrm{mm})$ & & & \\
3 weeks & $25.77 \pm 11.16$ & $24.60 \pm 15.92$ & 0.744 \\
6 Weeks & $24.43 \pm 11.11$ & $23.20 \pm 15.66$ & 0.726 \\
9 Weeks & $23.97 \pm 11.17$ & $22.77 \pm 15.68$ & 0.734 \\
12 weeks & $23.63 \pm 11.19$ & $22.43 \pm 15.67$ & 0.734 \\
Height (mm) & & & \\
3 weeks & $3.53 \pm 0.78$ & $3.30 \pm 1.02$ & 0.323 \\
6 Weeks & $2.47 \pm 0.59$ & $2.52 \pm 0.96$ & 0.809 \\
9 Weeks & $1.62 \pm 0.61$ & $1.55 \pm 0.87$ & 0.733 \\
12 weeks & $0.70 \pm 0.53$ & $0.65 \pm 0.68$ & 0.754 \\
\hline
\end{tabular}


Table-IV

Follow up of the lesions in group $A$ (TAC) and $B$ (5-FU+TAC) with percentage of improvement (Length/Height/Width)

\begin{tabular}{lccc}
\hline $\begin{array}{l}\text { Percentage of } \\
\text { improvement }\end{array}$ & Triamcinolone & $\begin{array}{c}\text { 5-FU+ } \\
\text { Triamcinolone }\end{array}$ & $\begin{array}{c}\text { P } \\
\text { value }\end{array}$ \\
\hline Length & $5.69 \%$ & $5.70 \%$ & 0.8984 \\
Width & $9.46 \%$ & $17.38 \%$ & 0.6857 \\
Height & $83.41 \%$ & $83.36 \%$ & 0.1328 \\
\hline
\end{tabular}

Table-V

Side effects of the patients showed in percentage

\begin{tabular}{lcc}
\hline Side effects & \multicolumn{2}{c}{ Percantage } \\
& Group A & Group B \\
\hline Telangiectasis & $20 \%$ & $0 \%$ \\
Pigmentation & $26.7 \%$ & $0 \%$ \\
Ulceration & $0 \%$ & $56.7 \%$ \\
Skin atrophy & $26.7 \%$ & $0 \%$ \\
\hline
\end{tabular}

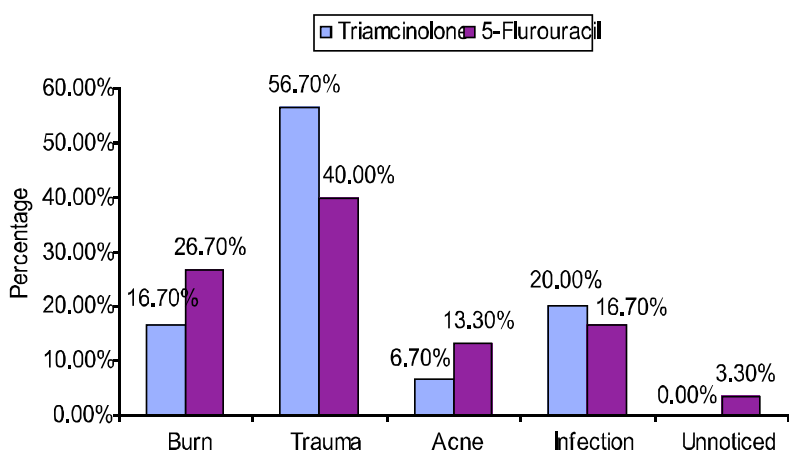

Fig. 1: Bar diagram showing predisposing factors in percentage in group $A$ (TAC) and group $B$ (5FU+TAC)

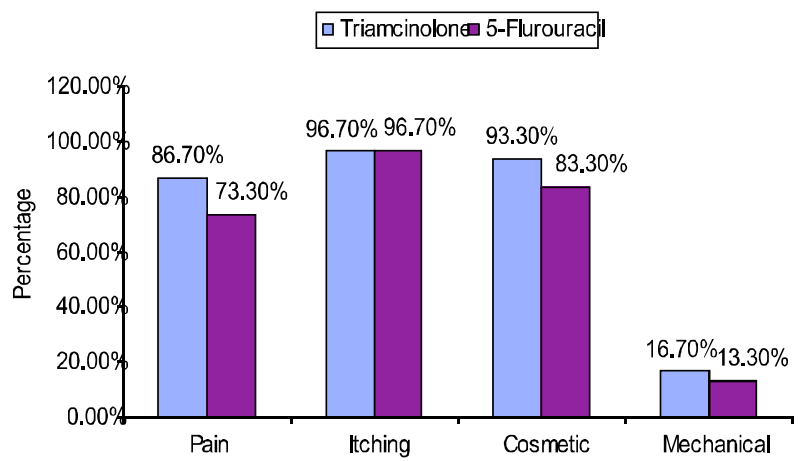

Fig. 2: Bar diagram showing presenting local symptoms in percentage in group $A$ (TAC) and group $B(5-F U+T A C)$

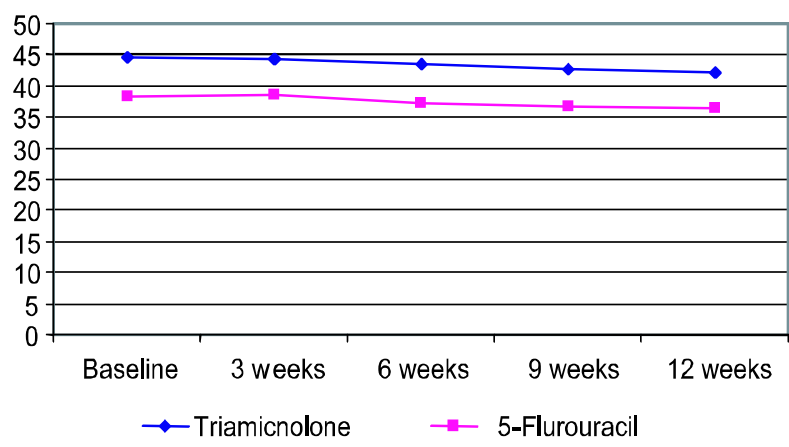

Fig. 3: Linear chart showing comparison of length lesions mean in group A (TAC) and group $B$ (5FU+TAC)

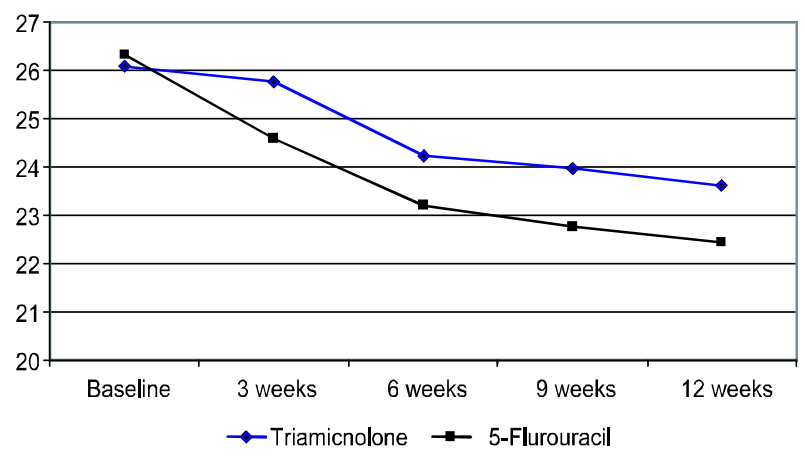

Fig. 4: Linear chart showing comparison of width of the lesions mean in group $A(T A C)$ and group $B$ (5-FU+TAC)

\section{Discussion:}

Keloid and hypertrophic scars are common problems especially in darker skinned people. Treatment has always been challenging. Over the years many modalities from topical to surgical have been tried. The results have been mixed. There have been reports of recurrence. Triamcinolone is the first line of treatment used over the years by physicians. It has been used by different specialties of doctors with effective results but recurrence and side effects are considerable. 5- Flurouracil is anti neoplastic drug and has recently been used for treatment of keloids and hypertrophic scars.

In the present study, Triamcinolone was given in one group (group A) of patients and other group received 5-Flurouracil with triamcinolone (group B). Each group consists of 30 patients. Mean lesion length was 44.67 $\mathrm{mm}$ in group A and $38.40 \mathrm{~mm}$ in group B. Mean lesion width was $26.10 \mathrm{~mm}$ in group A and 26.33 $\mathrm{mm}$ in group $\mathrm{B}$. $\mathrm{P}$ value was 0.950 which was 
statistically insignificant. Mean lesion height was $4.22 \mathrm{~mm}$ in group $\mathrm{A}$ and $3.93 \mathrm{~mm}$ in group B. $P$ value was 0.314 which was statistically insignificant. Erythema score at baseline were graded in 5 point scale by the investigators. In group A, 30\% patients graded as very severe group. 50\% got severe erythema and $20 \%$ got moderate erythema. In 12 weeks follow up $76.7 \%$ showed no erythema and $23.3 \%$ showed mild erythema. $\mathrm{P}$ value is less then 0.0001 which is highly significant. In group B $16.7 \%$ patients belongs to very severe erythema, $60 \%$ severe erythema, $20 \%$ in moderate erythema and $3.3 \%$ in mild erythema at base line. On 12 weeks $83.3 \%$ in no erythema ans $16.7 \%$ in mild erythema. P value is less then 0.0001 and highly significant. Induration score at baseline were graded in 5 point scale by investigator. In group A $30 \%$ patients graded as very severe group. $53.3 \%$ got severe induration and $16.7 \%$ got moderate induration. In 12 weeks $36.7 \%$ patients got mild induration and $63.3 \% \%$ got no induration. $\mathrm{P}$ value is less then 0.0001 which is highly significant. In group B $16.7 \%$ patients got very severe induration, $53.3 \%$ got severe induration and $30 \%$ got moderate induration. After injection at 12 weeks follow up no induration noted in $66.7 \%$ cases. $33.3 \%$ showed mild induration. $P$ value is less then 0.0001 which is highly significant. Pruritis score at baseline were graded in 5 point scale by investigator. In group A $33.3 \%$ patients graded as very severe group. 50\% got severe pruritis and $16.7 \%$ got moderate pruritis. On 12 weeks $83.3 \%$ got no preritis and $16.7 \%$ got mild pruritis. $P$ value is less then 0.0001 which is highly significant. In group B $46.7 \%$ patients got very severe pruritis, $40 \%$ got severe pruritis and $10 \%$ got moderate pruritis. On 12 weeks $83.3 \%$ patients got no pruritis and $16.7 \%$ patients complains mild pruritis. $\mathrm{P}$ value was $<0.0001$ which was highly significant. Comparing the demographic data and local symptoms and local examination revealed no significant difference between two groups. Few studies ${ }^{15-18}$ were carried out with this view and their demographic data in between groups were similar. In group A, from baseline $44.67 \mathrm{~mm}$ lesion length decreased to $42.03 \mathrm{~mm}$ at 12 weeks. There was $5.69 \%$ improvement in length in group A. In group B, similar result was observed. From mean $38.40 \mathrm{~mm}$ of baseline lesions decreases to $36.33 \mathrm{~mm}$. $5.70 \%$ improvement in length in group B noted. The width of the lesions in group A from baseline $26.10 \mathrm{~mm}$ lesion length decreased to $23.63 \mathrm{~mm}$ at 12 weeks. In group A, the width had $9.46 \%$ improvement. In group $B$, similar result was observed. From mean $26.33 \mathrm{~mm}$ of baseline lesions decreased to $22.43 \mathrm{~mm}$ at the end. $17.38 \%$ improvement noted there. The height of the lesions in both groups were plotted in table and baseline mean in compared with 12 weeks follow up value. In group A, from baseline $4.22 \mathrm{~mm}$ lesion height decrease to 12 weeks height was 0.70 Height reduction $83.41 \%$ occurs in group A and $P$ value was $<0.0001$ which was statistically significant. In group B, from baseline $3.93 \mathrm{~mm}$ lesion height decrease to 12 weeks height was 0.70 and $p$ value less than 0.0001 statistically significant. In group B there was $83.36 \%$ height reduction. Height reduction in both groups were found similar. In 2006, Asilian, Darougheh and Shariati ${ }^{18}$ carried out a study in Department of Dermatology, Isfahan University of Medical Sciences, Iran, and find that TAC+5-FU and 5FU+TAC+Pulsedye lasers group showed more statistically significant height reduction than that of TAC group. In 2009, Steven et al. ${ }^{15}$ carried out a study the found that patients who underwent the $5-\mathrm{FU} /$ steroid combination with excision had a $92 \%$ average reduction in lesion size compared with $73 \%$ in those patients who did not receive 5-FU. Patients who received intralesional 5-FU/steroid without excision had an average size reduction of $81 \%$. In 2007 , Darougheh, Asilian and Shariati ${ }^{17}$ carried out study over 40 patients and found that at the 8week and 12-week follow-up visits, both groups showed an acceptable improvement in nearly all parameters, but these were more significant in group B $(P<0.05$ for all, except pruritus and percentage of itch reduction). The results of our study were similar to the above mentioned studies. In Group A, 20\% patients showed telangiectasis. No patients in group B showed telangiectasis. In group A side effects of hypopigmentation noted in $26.7 \%$ of the patients. In group B, no patients showed 
pigment changes. No patients in group A showed ulceration. In $56.7 \%$ patient of group $\mathrm{B}$, ulceration was observed. Patients in group A complained skin atrophy $20 \%$ in 12 weeks. No patients in group B showed skin atrophy on $3,6,9$ and 12 weeks. In summary it reveals that triamcinlone group had side effects of telangiectasis skin atrophy and hypopigmentation in some patients. In group $B$, ulceration noted more than half of the patients. Steven et al (2009) ${ }^{15}$ found no significant adverse effects between two groups except few people who had telangiectasis in TAC group. Asilian, Darougheh and Shariati ${ }^{18}$ conclude that 5-FU had no systemic side effects during IL injection similar to our study. 5-FU had very few side effects like ulceration ${ }^{18}$. During follow up most of the adverse effects of IL injections were minimized. Lastly we can conclude that both the treatment modalities were effective and $\mathrm{TAC}+5-\mathrm{FU}$ had similar response in height reduction, which was similar to Steven et al. ${ }^{15}$. Very few side effects like telangiectasis, skin atrophy, hypopigmentation were noted group A. Ulceration was main side effects of group B. Therefore, we found no statistically significant advantage of one group over other in relation to their efficacy and side effects.

\section{Conclusion:}

Keloid and hypertrophic scars are common dermatological problems. They not only raise cosmetic concern but also at times are painful, pruritic, severely disfiguring and causing limitations in regular activities. Moreover, they are not easy to treat. Although many treatment modalities have been tried, but recurrence and treatment failures were observed in every single one. In our study comparing the efficacy of IL triamcinolone and 5-FU we conclude that 5 -FU had similar response like triamcinolone and overall efficacy of both the modalities were statistically similar and comparable. Regarding side effects trimcinolone had few side effects like hypo pigmentation, telangiectais and skin atrophy. 5-Flurouracil had side effects like ulceration in more that half patients. We can conclude that intralesional triamcinolone and 5-FU+triamcinolone both modalities are acceptable for treatment of keloids with fewer side effects.

\section{References:}

1. Kelly AP. Medical and surgical therapies for keloids. Dermatol Ther 2004; 17: 212-8.

2. Manuskiatti W, Fitzpatrick RE, Goldman MP. Energy density and numbers of treatment affect response of keloidal and hypertrophic sternotomy scars to the 585-nm flashlamp-pumped pulseddye laser. J Am Acad Dermatol 2001; 45: 557-65.

3. Tuan T, Nichter LS. The molecular basis of keloid and hypertrophic scar formation. Mol Med Today 1998; 4: 19-24.

4. Manuskiatti W, Fitzpatrick RE. Treatment response of keloidal and hypertrophic sternotomy scars: comparison among intralesional corticosteroid, 5-fluorouracil, and 585-nm flashlamp-pumped pulseddye laser treatments. Arch Dermatol 2002; 138: 1149-55.

5. Chan HH, Wong DSY, Ho WS. The use of pulsed dye laser for the prevention and treatment of hypertrophic scars in Chinese persons. Dermatol Surg 2004; 30: 987-94.

6. Lee TY, Chin GS, Kim WJ. Expression of transforming growth factor beta 1,2 and 3 proteins in keloids. Ann Plast Surg 1999; 43: 179-80.

7. Polo M, Smith DD, Kim YJ. Effect of TGF- b2 on proliferative fibroblast cell kinetics. Ann Plast Surg 1999; 43: 185-90.

8. Kontochristopoulos G, Stefanaki C, Panagiotopoulos A. Intralesional 5-fluorouracil in the treatment of keloids: an open clinical and histopathologic study. J Am Acad Dermatol 2005; 52: 474-9.

9. Al-Attar A, Mess S, Thomassen JM, Kauffman CL, Davison SP. Keloid pathogenesis and treatment. Plast Reconstr Surg 2006; 117: 286-300.

10. Asilian A, Darougheh A, Shariati F. New combination of triamcinolone, 5-fluorouracil, and pulsed-dye laser for treatment of keloid and hypertrophic scars. Dermatol Surg 2006; 32: 907 15.

11. Ghoshal K, Jacob ST. An alternative molecular mechanism of action of 5-fluoruracil, a potent anti-cancer drug. Biochem Pharmacol 1997; 53: 1569.

12. Blumenkranz MS, Claflin A, Hajek AS. Selection of the therapeutic agents for intra-ocular proliferative disease: cell culture evaluation. Arch Ophthalmol 1984; 102: 598-604.

13. Shaffer JJ, Taylor SC, Cook-Bolden F. Keloid scars: a review with a critical look at therapeutic options. J Am Acad Dermatol 2002; 46 (suppl): 63-97. 
14. Apikian M, Goodman G. Intralesional 5-flurouracil in the treatment of keloid scras. Australas $\mathrm{J}$ Dermatol 2004; 45: 140-3.

15. Steven PD, Joseph HD, Mark WC, Smitha S, Antai W, Amy C. Efficacy of intralesional 5-Fluorouracil and triamcinolone in the treatment of keloids. Aesthetic Surg J 2009; 29: 40-46.

16. Sharad P, Narendra P. efficacy of 5-flurouracil with or without triamcinolone in treating keloids. Cutaneous and aesthetic Surg 2008; 1: 36.
17. Darougheh A, Asilian A, Shariati F. Intralesional triamcinolone alone or in combination with 5fluorouracil for the treatment of keloid and hypertrophic scars. Clin Exp Dermatol 2007; 34: 219-223.

18. Asilian A, Darougheh A, Shariati F. New Combination of triamcinolone, 5-fluorouracil, and pulsed-dye laser for treatment of keloid and hypertrophic scars. Dermatol Surg 2006; 32: $907-$ 15. 